\title{
Pelatihan Pembuatan Aplikasi E-Learning (Edmodo) Pada Guru SMP IT Lantabur Kota Pagar Alam
}

\author{
Siti Muntari ${ }^{1}$, Sasmita $^{2}$ \\ Program Studi Teknik Informatika; Sekolah Tinggi Teknologi Pagaralam (STTP) \\ Jl. M. Siagim No.75 Kel. Karang Dalo, Dempo Tengah, Kota Pagar Alam \\ Telp/Fax: (0730) 621916 \\ e-mail:. muntariaza@gmail.com¹. sasmitha661@gmail.com².
}

\begin{abstract}
Abstrak
Sistem pembelajaran yang baik harus dilakukan dengan dukungan sistem dan sarana pembelajaran yang sangat baik agar output yang dihasilkan sesuai dengan harapan, keberhasilan pembelajaran tentu dipengaruhi oleh pengajar dan sarana yang mendukungnya. Pimpinan SMP IT Lantabur sangat menyadari sarana pendukung menjadi faktor pendukung kesuksesan, sehingga SMP IT Lantabur dan LPPM STTP melakukan pengabdian dengan melakukan pelatihan elearning dengan Edmodo bagi Guru SMP IT Lantabur. Metode yang digunakan adalah ceramah dan praktek secara langsung, supaya pelatihan berjalan sesuai harapan sebelum pelatihan dilakukan pre tes untuk mengetahui tingkat pemahaman peserta terhadap aplikasi edmodo, ternyata hasilnya tidak ada peserta yang pernah melakukan pembelajaran dengan edmodo sehingga mereka belum memahaminya sehingga pembelajaran harus dilakukan dengan detail dan baik, setelah pelaksanaan pelatihan kembali dilakukan tes untuk mengetahui sejauh mana peserta menerima materi yang telah disampaikan, hasilnya semua peserta mampu membuat dan menyiapkan pembelajaran menggunakan edmodo.
\end{abstract}

Kata kunci-Pembelajaran, SMP, Pengabdian, Edmodo, Pelatihan, Materi.

\section{PENDAHULUAN.}

Arah perkembangan Teknologi informasi dan komunikasi khususnya teknologi yang mendukung terlaksananya kegiatan (pendukung) pembelajaran saat ini sangat banyak dan menawarkan kemudahan-kemudahan sesuai ke unggulan masing-masing, salah satunya adalah $e$ learning yang bisa di manfaatkan sebagai sarana pembuatan aplikasi pengolahan data pembelajaran. Media ini sangat banyak sekali dipergunakan di sebagai sarana pengolahan data yang sangat familiar pada bidang pendidikan jarak jauh (PJJ), dimana pembelajaran dapat dilakukan guru dan murid dimana saja.

Penggunaan e-learning (edmodo) sebagai media/sarana pembuatan aplikasi pengolahan data pembelajaran ini sangat di sarankan karena memiliki menu-menu yang sesuai dengan standar yang di sarankan oleh para ahli yang kompeten, sehingga pada saat penyusunan pada e-learning dengan edmodo ini pembuat aplikasi tinggal klik menu-menu yang di maksud maka di dapat hasil tulisan (pengolah data) yang baik (standar), selain itu edmodo merupakan software pengolah data pembelajaran yang mudah di dapat dan murah, selain itu apa bila ingin meng-upgrade, atau mengganti ke versi terbaru developer menyediakan dengan mudah. Dan saat ini telah banyak versi yang semakin memudahkan para penggunanya dan membuat peserta pendidikan semakin bersemangat.

SMP IT Lantabur merupakan lembaga pendidikan berbasis keislaman yang sangat mengikuti perkembangan pendukung pembelajaran sehingga sangat dibutuhkan sistem e-learning untuk pelaksanaan proses pembelajaran yang serba digital. Dari pemaparan diatas dituntut agar para peserta (Guru) SMP IT Lantabur harus selalu meningkatkan kualitas pembelajaran dengan menggunakan semua resource terkait, sehingga dipandang perlu untuk diadakan pelatihan pembuatan aplikasi pengolahan data pembelajaran menggunakan sarana pendukung pembelajaran berbasis e-learning menggunakan edmodo. 


\section{METODE.}

Pengabdian (PkM) ini dilakukan civitas STTP dilakukan secara mandiri, dan berbarengan dengan kuliah kerja nyata yang dilakukan mahasiswa sehingga pada pelaksanaanya mahasiswa membantu dosen yang melaksanakan pengabdian. Metodologi yang dipergunakan pada pelaksanaan kegiatan Pengabdian kepada masyarakat $(\mathrm{PkM})$ ini peserta menyimak (menonton) bersama, membaca bersama (modul pelatihan), memahami tools aplikasi (Software) dan berinteraksi secara langsung (Aplikatif) dengan software.

\subsection{Pengabdian Pada Masyarakat (PkM).}

Pengabdian masyarakat, suatu kegiatan yang memiliki bertujuan membantu masyarakat tertentu dalam beberapa aktivitas tanpa berharap imbalan bentuk apapun. Secara umum program ini dirancang universitas (perguruan tinggi) yang ada di Indonesia untuk memberikan kontribusi nyata bagi masyarakat, khususnya dalam mengembangkan kesejahteraan dan kemajuan masyarakat. Kegiatan ini merupakan salah satu bagian Tri Dharma Perguruan Tinggi. Bentukbentuk kegiatannya: Bakti Sosial dan Mengajar. Tujuannya:

1. Menciptakan dan mengembangkan inovasi teknologi tinggi untuk mendorong pembangunan ekonomi dengan melakukan komersialisasi hasil penelitian yang dilakukan di kampus;

2. Menyampaikan solusi berdasarkan hasil kajian akademik atas kebutuhan, tantangan, atau persoalan yang dihadapi masyarakat, baik secara langsung maupun tidak langsung;

3. Melakukan kegiatan yang mampu mengentaskan masyarakat tersisih (preferential option for the poor) pada semua strata, yaitu masyarakat tersisih secara ekonomi, sosial dan budaya;

4. Melakukan alih teknologi, ilmu dan seni kepada masyarakat untuk pengembangan martabat manusia dan kelestarian sumber daya alam yang harus dilestarikan.

5. Meningkatkan daya saing dan kemampuan masyarakat.

\subsection{E-Learning.}

Sistem pembelajaran elektronik atau dikenal dengan istilah "e-learning" merupakan inovasi baru pada pembelajaran. Menurut (Darmawan, 2014: 10) e-learning merupakan aplikasi internet yang dapat menghubungkan pendidik dan perserta didik dalam sebuah ruang belajar online. Cisco (2001) yang di kutip oleh Darmawan (2014: 27) menjelaskan filosofis E-learning sebagai berikut. Pertama, E-learning merupakan penyampaian informasi, komunikasi, pendidikan, pelatihan secara on-line. Kedua, E-learning menyediakan seperangkat alat yang dapat memperkaya nilai belajar secara konvensional (model belajar konvensional, kajian terhadap buku teks, CD-ROM, dan pelatihan berbasis komputer), sehingga dapat menjawab tantangan perkembangan globalisasi.

\subsection{Edmodo.}

Edmodo dikembangkan pada akhir tahun 2008 Nic Borg dan Jeff Ohara berkeyakinan perlunya dikembangkan lingkungan sekolah yang terhubung dengan semua aktifitas didunia. sehingga tidak ada kesenjangan antara kehidupan siswa di sekolah dengan kehidupan kesehariannya. Edmodo adalah media social network microblogging yang aman bagi siswa dan guru. Pada situs ini orang tua pun dapat bergabung serta berkomunikasi dengan guru dan orang tua siswa lain, selain itu tentu saja dengan putra atau putri mereka sendiri. Sekarang Edmodo sudah berkembang pesat dan sudah memiliki kurang lebih 7 juta akun terdiri dari guru dan murid. Pada tahun 2010 Edmodo meluncurkan "subjek" dan "penerbit" masyarakat, media digital perpustakaan, pusat bantuan, dan rekening induk untuk berkomunikasi dengan guru, orang tua, dan siswa. Edmodo merupakan jejaring sosial untuk pembelajaran berbasis Learning Managent System (LMS). Edmodo memberi fasilitas bagi guru, murid tempat aman untuk berkomunikasi, berkolaborasi, berbagi konten dan aplikasi pembelajaran, pekerjaan rumah (PR) bagi siswa, diskusi dalam kelas virtual, ulangan secara online, nilai dan masih banyak lagi. Intinya edmodo menyediakan semua yang bisa kita lakukan dikelas bersama siswa dalam kegiatan pembelajaran ditambah fasilitas bagi orang tua bisa memantau semua aktifitas anak di edmodo asalkan punya parent code untuk anaknya. Edmodo adalah sebuah situs yang diperuntukan bagi pendidik untuk membuat kelas virtual. Situs tersebut gratis dan gampang digunakannya selama seorang guru dan 
murid bisa terhubung dengan internet. Edmodo merupakan sebuah jawaban bagi sebuah ruang kelas virtual nyaman dan aman, dikarenakan :

1. Siswa melakukan interaksi dalam pantauan gurunya (bebas cyber crime dan cyber bullying).

2. Guru dapat mengunci siswa, dengan demikian ia hanya bisa membaca dan tidak bisa berkomentar pada seisi 'kelas' namun tetap ia bisa berkomunikasi langsung dengan gurunya.

3. Tidak ada orang luar bisa masuk dan melihat kelas virtual yang dibuat seorang guru tanpa mendapat kode khusus dari guru yang bersangkutan.

4. Guru dapat memulai pertanyaan, menaruh foto atau video, menaruh presentasi bahan ajar, yang kesemuanya bebas untuk diunduh oleh siswa dan dikomentari.

5. Murid bisa kembali kapan saja untuk mengulang materi yang diberikan guru, bahkan PR bisa diberikan melalui edmodo.

6. Murid juga bisa mengumpulkan PR lewat edmodo, tinggal unggah saja. Edmodo bisa dipadukan dengan situs lain seperti wall wisher, glogster dan lain sebagainya.

7. Guru bisa menaruh nilai dari pekerjaan siswa sebagai acuan bagi siswa.

8. Kelas virtual yang dibuat seorang guru tidak terbatas, guru bisa menaruh bahan ajar untuk digunakan di angkatan atau tahun ajaran berikutnya.

9. Siswa bisa bekerja sama dengan siswa lain dalam grup kecil yang dibentuk oleh gurunya.

10. Saat mengerjakan sebuah proyek bersama mereka bisa menaruh semua dokumen yang diperlukan dalam pengerjaannya.

11. Edmodo memungkinkan guru menaruh bahan ajar yang sangat berguna bagi siswa yang tidak masuk atau berhalangan saat melakukan tatap muka.

12. Siswa pendiam bisa bebas berkata dan berpendapat tanpa khawatir dipermalukan sementara si anak tipe aktif bisa posting pertanyaan kapan saja asal ia terhubung dengan internet.

13. Guru dapat mengajarkan tata cara yang berlaku di dunia maya seperti cara berkomentar dan sederet tata karma di dunia maya yang perlu siswanya ketahui.

\subsection{Pre \& Pos Tes.}

Pre tes yaitu suatu bentuk pertanyaan, yang dilontarkan guru kepada muridnya sebelum memulai suatu pelajaran. Pertanyaan yang ditanya adalah materi yang akan diajar pada hari itu (materi baru). Pertanyaan itu biasanya dilakukan guru di awal pembukaan pelajaran. Pre tes diberikan dengan maksud untuk mengetahui apakah ada diantara murid yang sudah mengetahui mengenai materi yang akan diajarkan. Pre tes juga bisa di artikan sebagai kegiatan menguji tingkatan pengetahuan siswa terhadap materi yang akan disampaikan, kegiatan pre test dilakukan sebelum kegiatan pengajaran diberikan. Adapun manfaat dari diadakannya pre tes adalah untuk mengetahui kemampuan awal siswa mengenai pelajaran yang disampaikan. Dengan mengetahui kemampuan awal siswa ini, guru akan dapat menentukan cara penyampaian pelajaran yang akan di tempuhnya nanti.

Post tes merupakan bentuk pertanyaan yang diberikan setelah pelajaran/materi telah disampaikan. Singkatnya, post tes adalah evalausi akhir saat materi yang di ajarkan pada hari itu telah diberikan yang mana seorang guru memberikan post tes dengan maksud apakah murid sudah mengerti dan memahami mengenai materi yang baru saja diberikan pada hari itu. Manfaat dari diadakannya post tes ini adalah untuk memperoleh gambaran tentang kemampuan yang dicapai setelah berakhirnya penyampaian pelajaran. Hasil post tes ini dibandingkan dengan hasil pre tes yang telah dilakukan sehingga akan diketahui seberapa jauh efek atau pengaruh dari pengajaran yang telah dilakukan, disamping sekaligus dapat diketahui bagian bagian mana dari bahan pengajaran yang masih belum dipahami oleh sebagian besar siswa.

\subsection{Penyelesaian Masalah.}

Sesui dengan permasalahan ini maka perlu dilakukan pelatihan pembuatan aplikasi elearning pada SMPN IT Lantabur, karena SMP IT Lantabur menerapkan pembelajaran berbasis digital, pelatihan dilakukan langsung praktek menggunakan edmodo sehingga peserta dapat langsung memasukan materi pelajaran dalam kelas ke dalam aplikasi edmodo yang disiapkan pelatihan dilakukan satu hari, pada laboratorium pembelajaran SMP IT Lantabur di Pagar Alam. 


\section{PEMBAHASAN DAN HASIL.}

3.1. Realisasi \& Pemecahan Masalah.

Pelatihan pembuatan aplikasi e-learning dengan menggunakan edmodo ini merupakan jawaban atas pemasalahan pengajaran SMP IT Lantabur yang menerapkan sistem pembelajaran digital, pelatihan dilakukan selama satu hari dilakukan pada seluruh Guru dan Pegawai SMP IT Lantabur Kota Pagar Alam, yang mana rincian kegiatannya tersusun seperti tabel 1, dibawah ini:

Tabel 1. Jadwal Kegiatan

\begin{tabular}{|c|l|c|}
\hline Waktu & \multicolumn{1}{|c|}{ Materi } & Penyaji \\
\hline $08.00-09.00$ & $\begin{array}{l}\text { Pre Test } \\
\text { Pendahuluan tentang e-learning dan penjelasan tools } \\
\text { edmodo. }\end{array}$ & Siti Muntari, \\
& Sasmita \\
$09.30-12.00$ & $\begin{array}{l}\text { Memasukan data pelajaran kedalam edmodo, dengan } \\
\text { mengacu pada modul dan bimbingan narasumber. }\end{array}$ & \\
$12.00-12.30$ & Ishoma & \\
$12.30-13.00$ & Post-test
\end{tabular}

Tabel 1. Merupakan kegiatan yang dilakukan pada saat pengabdian, kegiatan diawali dengan dilakukannya pre tes untuk mengukur tingkat pemahaman peserta pelatihan terhadapa aplikasi edmodo, yang menjadi basis aplikasi e-learning yang dibangun. Dan pre tes juga menjadi titik awal acuan narasumber dalam memberikan latihan sehingga narasumber terarah dalam menyampaikan materi karena sesuai dengan kebutuhan dari peserta pelatihan. Berikutnya dilakukan pemberian materi secara teori dalam hal ini menjelaskan tentang peluang e-learning kedepan dan penjelasan awal tentang cara menggunakan edmodo, menjelaskan tentang tools dan fitur yang ada pada edmodo, diuraikan fungsi dan manfaatnya sampai seluruh peserta memahami.

Berikutnya setelah seluruh peserta mengenal dengan baik konsep e-learning dan tools pembelajaran menggunakan edmodo, berikutnya peserta melakukan praktek secara langsung menggunakan edmodo, dengan mengacu pada modul dan bimbingan narasumber, dimana peserta diminta untuk meniru seluruh langkah-langkah pembuatan aplikasi sehingga terbentuk e-learning yang siap dipergunakan oleh siswa untuk belajar, jika peserta menemukan permasalahan dan mengalami kesulitan memahami modul dapat langsung bertanya kepada narasumber dalam pelatihan. Terakhir setelah dinyatakan menurut pengamatan narasumber peserta pelatihan menguasi materi pelatihan sebelum penutupan dilakukan kembali tes, pos tes untuk mengetahui tingkat keberhasilan yang dilakukan, seberapa paham peserta terhadap materi yang disampaikan dalam pelatihan nantinya menjadi bahan masukan bagi penyelenggaraan pengabdian berikutnya.

\subsection{Pembahasan \& Hasil.}

Pembahasan berdasarkan poin 3.1, merupakan uraian realisasi dan pemecahan yang dihadapi SMP IT Lantabur Kota Pagar Alam dengan dilakukan pengabdian bertema pelatihan pembuatan aplikasi e-learning menggunakan edmodo versi terbaru, dengan hasil pelaksanaan sebagai berikut.

Pelatihan didahului dengan diadakan pre tes, hasilnya seluruh peserta $(100 \%)$ paham dan mengetahui tentang e-learning tetapi belum pernah menggunakan atau mengaplikasikannya dalam pembelajaran sehingga berdasarkan simpulan ini pelatihan harus dilakukan dan tujuan dari pre tes ini mengetahui pemahaman peserta terhadap edmodo ini menjadi ukuran bagi narasumber harus memberikan pelatihan dari mana, maka berdasarkan pre tes ini maka pelatihan harus dilakukan dari awal sekali dengan mengenalkan terlebih dahulu teori pembuatan aplikasi edmodo, dan hasilnya peserta menjadi paham tujuan dari pre tes sehingga selain narasumber fokus apa yang harus diajarkan, peserta pun mendapat pemahaman yang rinci dan menyeluruh karena sistem secara keseluruhan dijelaskan secara jelas oleh narasumber.

Kedua, tentu setelah diketahui kebutuhan peserta pelatihan dari hari pre tes, diuraikan secara teori tentang e-learningnya sendiri, secara konsep dan secara teknis, prosfek dan peluangnya pada masa mendatang, pendidikan berbasis e-learning (digital) sangat tinggi karena kedepan pendidikan jarak jauh (PJJ) merupakan sistem pendidikan yang diminati oleh masyarakat, 
pendidikan diperkirakan didahului dengan dicampur antara pendidikan secara langsung tatap muka dalam kelas dan pendidikan jarak jauh, diyakini dimasa yang mendatang pendidikan lebih banyak menggunakan sistem digital yang bisa dilaksanakan dimana saja, kapan saja dan jarak jauh. Pada bagian ini juga dikelankan tools dan fitur edmodo.

Ketiga, peserta pelatihan diminta untuk praktek langsung mengaplikasikan teori penjelasan tahap kedua, ke dalam aplikasi edmodo secara langsung dengan mengacu langkah-langkah pada modul dan bertanya secara langsung kepada narasumber yang mendampingi, dan dari pengamatan narasumber semua perserta mampu mengaplikasikan teori ke dalam edmodo, terlihat diakhir kegiatan e-learning berbasis edmodo SMP IT Lantabur dapat terbentuk.

Terakhir, pada kegiatan ini kembali dilakukan pos tes kepada seluruh peserta pelatihan hal ini dilakukan untuk memahami tingkat pemahaman peserta terhadap materi yang disampaikan narasumber pada pelatihan ini, dimana secara kasat mata peserta pelatihan sudah bisa membuat aplikasi edmodo pembelajaran, dikuatkan dengan pos tes ini benar $100 \%$ peserta pelatihan sudah bisa mengolah data di edmodo, ini artinya SMP IT Lantabur telah siap untuk melaksanakan sistem pembelajaran daring, yang berbasis internet, siswa dimana saja dengan akunnya dapat mengakses pelajaran atau materi yang dibuat guru mata pelajaran. Berikut jika dimasukan ke dalam tabel, terdeskripsi dalam tabel 2. Keberhasilan kegiatan pelatihan.

Tabel 2. Keberhasilan Pelaksanaan Kegiatan

\begin{tabular}{|l|l|}
\hline \multicolumn{1}{|c|}{ Materi } & \multicolumn{1}{|c|}{ Hasil } \\
\hline Pre tes & $\begin{array}{l}\text { Peserta memahi maksud dan diadakannya pelatihan sehingga } \\
\text { menjadi fokus belajar dari materi yang disampaikan narasumber. }\end{array}$ \\
\hline Pendahuluan e-learning & $\begin{array}{l}\text { Memahami prosfek sistem pembelajaran dari pada masa yang } \\
\text { mendatang, sehingga pelatihan ini menjadi wajib dilakukan. }\end{array}$ \\
\hline Pengenalan dasar edmodo & $\begin{array}{l}\text { Peserta paham cara membuat aplikasi e-learning berbasis edmodo, } \\
\text { didhului penjelasan cara membuat aku, cara upload, cara } \\
\text { memperbaiki, memperkenalkan tools membuat tugas, PR, absen, } \\
\text { dan sebagainya. }\end{array}$ \\
\hline Praktek pada edmodo & $\begin{array}{l}\text { Peserta mampu membuat aplikasi berdasarkan penjelasan } \\
\text { sebelumnya sehingga terbentuk aplikasi sarana pembelajaran yang } \\
\text { siap dipergunakan oleh siswa. }\end{array}$ \\
\hline Pos tes & $\begin{array}{l}\text { Merupakan terakhir yang dilakukan narasumber untuk mengatahui } \\
\text { tingkat pemahaman atau daya serap materi oleh semua peserta dan } \\
\text { hasilnya 100\% peserta bisa menjalankan edmodo dan telah } \\
\text { memiliki akun edmodo tiap guru mata pelajaran. }\end{array}$ \\
\hline
\end{tabular}

Hasil akhir dari pelatihan ini seluruh guru mata pelajaran telah memiliki akun edmodo dan mampu mengolah data pelajaran dalam edmodo, melakukan perbaikan tampilan dan memasukan fitur tambahan sehingga menjadi lebih menarik, bahkan peserta telah mampu dengan baik membuat tugas, PR, berbagai tes menggunakan fitur yang ada pada edmodo, mampu berkomunikasi dengan orang tua dan siswa yang menjadi peserta didiknya, sehingga seluruh komponen penilaian yang ada bisa diidentifikasi dan dikalkulasi dengan baik, dengan bantuan aplikasi edmodo ini, sehingga bisa diidentifikasi berikut merupakan hasil akhirnya, yaitu:

a. Peserta Guru SMP IT Lantabur mempunyai pengetahuan dan pemahaman yang baik tentang teknologi e-learning dengan baik.

b. Seluruh Guru peserta pelatihan memahami sistem pembelajaran jarak jauh (PJJ) dan berbasis Digital pada masa mendatang.

c. Seluruh Guru peserta pelatihan menjadi sangat paham terhadap teknologi informasi yang lebih aplikatif untuk mendukung proses pembelajaran yang diadakan dalam kelas dan mampu memilih sarana tersebut sesuai dengan keperluan.

d. Pimpinan SMP IT Lantabur menjadi terbantu dengan adanya kegiatan pengabdian ini sehingga meringankan biaya pelatihan. 
e. Para siswa dan siswi peserta pelatihan dengan adanya e-learning lebih memahami lagi tentang aplikasi pembelajaran TIK yang disampaikan oleh guru menjadi lebih baik dan jauh lebih memahami secara lebih aplikatif dalam pembelajaran.

\section{KESIMPULAN}

Pada pelaksanaan pengabdian masyarakat ini yang dilakukan di SMP IT Lantabur ini, dengan tujuan melatih Guru dan pengajar dalam melakukan pembelajaran berbasis digital melalui aplikasi edmodo didapatkan kesimpulan sebagai berikut:

a. Pada melakukan proses pembelajaran dengan cara belajar aplikasi secara langsung ternyata sudah mampu meningkatkan semangat belajar menjadi lebih baik (giat).

b. Menambah softskills para pengajar selain sistem pembelajaran yang konvensional sekarang guru memahami pembelajaran berbasis e-learning sehingga SMP IT Lantabur menjadi lebih siap menjawab tantangan yang mengarah pada pendidikan jarak jauh.

c. Meningkatkan rasa percaya diri para guru peserta pelatihan dengan kemampuannya bidang TIK ketika terjun di masyarakat atau pada saat memberikan pembelajaran.

d. Membantu guru pelajaran TIK dalam hal memahamkan Guru Non TIK terhadap terhadap suatu aplikasi tertentu yang mendukung sarana pembelajaran.

e. Memeberikan pengalaman baru pada pengabdi dalam mengajar Guru yang secara usia lebih dewasa dari segi usia.

\section{SARAN}

Maka dari pengalaman yang dilihat dan dirasakan penulis saat melakukan pengabdian ini maka, penulis dalam hal ini bisa memberikan sarana bagi seluruh elemen:

a. Waktu pengabdian dilakukan seharusnya sesuai dengan keperluan dan materi yang disampaikan, sehingga pengabdi menjadi lebih leluasa menyampaikan materi tanpa takut waktu habis.

b. Sistem pelaksanaan dan pengelolaan pelaksanaan PkM lebih diperbaiki lagi.

c. Sistem dan langkah pelaksanaan diatur sedemikian rupa sehingga tidak terkesan saling menunggu dalam pelaksanaanya.

\section{UCAPAN TERIMA KASIH}

Terima kasih disampaikan kepada STTP, LPPM, Para dosen, Mahasiswa yang membantu, para peserta pelatihan dan pimpinan SMP IT lantabur.

\section{DAFTAR PUSTAKA}

[1] Basori. 2013. Pemanfaatan social Network "EDMODO" Dalam Membantu Perkuliahan Teori Bodi Otomotif Di Prodi PTM JPTK FKIP UNS, JIPTEK.

[2] Deni Darmawan. 2012. Inovasi Pendidikan. Bandung : PT Remaja Rosdakarya.

[3] Muslim, B. 2018. Pelatihan aplikasi editing video dengan filmora., Laporan Pengabdian Kepada Masyarakat, LPPM STT Pagaralam.

[4] Muslim, B. 2018. Pelatihan Pembuatan Blog Bagi Guru Ma Ponpes Darul Mutaqin Kota Pagaralam. NGABDIMAS. Vol 1. No.1. Bulan Juni, Hal. 6-11

[5] B. Muslim, Pengantar teknologi informasi. Yogyakarta: Deepublish, 2017.

[6] Muslim, B. (2018). Analisis system informasi (SI) terintegrasi di Perguruan Tinggi (PT) (Studi Kasus: STT Pagaralam). Jurnal Teknologi Informasi MURA, Vol 10. Page 83-91.

[7] Muslim, B (2014). Analisis rencana aplikasi teknologi informasi pada STT Pagar Alam. Proseding semnastik dan Magma. Issue: Aplikasi Teknologi dan sistem Informasi. PPP UBD Pres. Pages 397-404. 
[8] Hutchinson E. Sarah and Sawyer C. Stacey, 2000, Computers, Communications \& Information, McGraw Hill Companies Inc.

[9] Indonesia Services Education HP Tim, 2001, Manajemen Sistem Belajar Di Dunia Maya, Majalah Info Komputer.

[10] M.H Jogiyanto, 1995, Pengenalan Komputer, Andi Offset Yogyakarta.

[11] Horsley, M., Knight, B., \& Huntly, H. 2010. The role of textbooks and other teaching and learning resources in higher education in Australia: Change and continuity in supporting learning. IARTEM 1-Journal. 3(2). 43-61.

[12] Sadiman, A.S., Rahardjo, R., Haryono, A., \& Rahardjito. 2006. Media pendidikan: Pengertian, pengembangan, dan pemanfaatan. Jakarta: Rajagrafindo Persada.

[13] Menristekdikti. 2016. Panduan Pelaksanaan Penelitian dan Pengabdian Masyarakat di Perguruan Tinggi Edisi X Tahun 2016. hlm. 4

[14] Isro'Mukti, Y. (2017). Sistem Informasi Madrasah Aliyah Negeri Pagar Alam Berbasis Web. Indonesian Journal of Computer Science, 6(2), 192-205.

[15] Mukti, Y. (2017). Perencanaan Strategis Sistem Informasi Dan Teknologi Informasi Pada Sekolah Menengah Kejuruan Negeri 2 Pagar Alam. JURNAL ILMIAH BETRIK: Besemah Teknologi Informasi dan Komputer, 8(02), 83-92.

[16] Arif, A., \& Mukti, Y. (2017). Rancang Bangun Website Sekolah Menengah Pertama (SMP) Negeri 8 Kota Pagar Alam. JURNAL ILMIAH BETRIK: Besemah Teknologi Informasi dan Komputer, 8(03), 156-165.

[17] Isro'Mukti, Y. (2018, October). Sistem Informasi Manajemen Aset Sekolah Tinggi Teknologi Pagaralam Berbasis Web. In Seminar Nasional Teknologi Informasi dan Komunikasi (SEMNASTIK) (Vol. 1, No. 1, pp. 632-638).

[18] Mukti, Y. (2018). Rancang Bangun Website Sekolah Dengan Metode User Centered Design (UCD). JURNAL ILMIAH BETRIK: Besemah Teknologi Informasi dan Komputer, 9(02), 84-95.

[19] Mukti, Y. (2018). Pelatihan Maintance Komputer SMAN Pagar Gunung. NGABDIMAS, $1(1), 47-51$.

[20] Mukti, Y. I. (2019). Implementasi Jaringan Hotspot Kampus Menggunakan Router Mikrotik. Indonesian Journal of Computer Science, 8(2), 130-138.

[21] Mukti, Y. I., \& Puspita, D. (2019). Sistem Informasi Peringatan Dini Bencana Pada Kota Pagar Alam Berbasis Mobile. Jusikom: Jurnal Sistem Komputer Musirawas, 4(2), 65-74.

[22] Mukti, Y. I. (2019). SISTEM INFORMASI MONITORING KESEHATAN MASYARAKAT BERBASIS WEB MENGGUNAKAN METODE UNIFED MODELLING LANGUAGE. Jusikom: Jurnal Sistem Komputer Musirawas, 4(1), 1-8.

[23] Mukti, Y. I., \& Puspita, D. (2019, December). Web Based Disaster Early Warning System on Pagar Alam City. In Conference SENATIK STT Adisutjipto Yogyakarta (Vol. 5, pp. 309-316).

[24] Isro'Mukti, Y., \& Puspita, D. WEB BASED DISASTER EARLY WARNING SYSTEM ON PAGAR ALAM CITY.

[25] Puspita, D., \& Isro'Mukti, Y. (2019, December). Web-Based Culture Information System of Literature Besemah City of Pagar Alam. In Conference SENATIK STT Adisutjipto Yogyakarta (Vol. 5, pp. 303-308). 